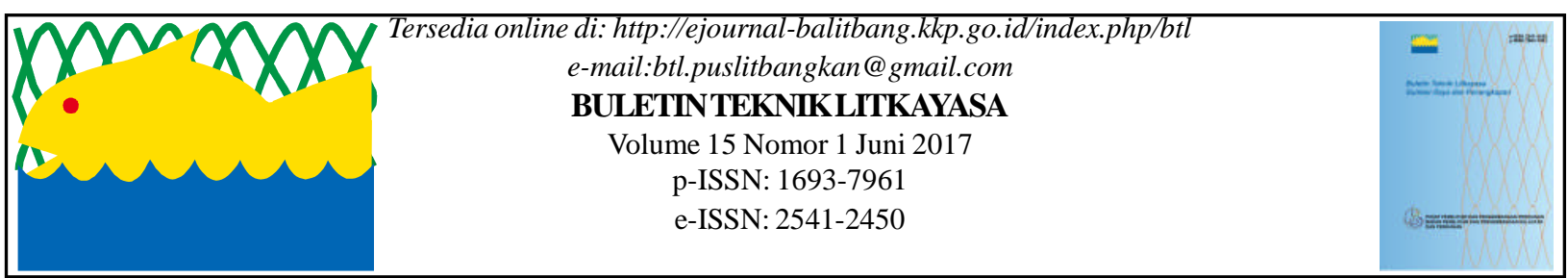

\title{
RANCANG BANGUN KEREKAYASAAN ALAT PENGUKUR KARAPAS RAJUNGAN
}

\author{
Achmad Djunaidi', Purwanto dan Kamis \\ ${ }^{1}$ Teknisi Litkayasa pada Balai Besar Penangkapan Ikan, Semarang \\ Teregistrasi I tanggal: 06 Maret 2017; Diterima setelah perbaikan tanggal: 08 Juni 2017; \\ Disetujui terbit tanggal: 13 Juni 2017
}

\section{PENDAHULUAN}

Peraturan Menteri Kelautan Perikanan (Permen KP) No. 1 tahun 2015 dijelaskan diantaranya adalah bahwa keberadaan dan ketersediaan rajungan (Portunus pelagicus) telah mengalami penurunan populasi,sehingga perlu dilakukan pembatasan penangkapan. Selanjutnya dalam pasal 2 dijelaskan bahwa setiap orang dilarang melakukan penangkapan rajungan (Portunus pelagicus) dalam keadaan bertelur. Pada pasal 3 dijelaskan diantaranya adalah penangkapan rajungan dapat dilakukan dengan ukuran lebar karapas $>10 \mathrm{~cm}$ (diatas sepuluh $\mathrm{cm}$ ). PerMen tersebut perlu didukung dengan pemantauan dalam pengumpulan data stok rajungan. Data yang dikumpulkan bertujuan untuk menyediakan informasi terbaru mengenai status stok rajungan sebagai dasar para pembuat keputusan dan pemangku kepentingan yang mencakup tentang Prosedur Operasi Standar untuk pencatatan data pada daerah penangkapan rajungan, lebar karapas, jenis kelamin dan tingkat kematangan. Hal tersebut diperlukan adanya seperangkat standar untuk proses pengumpulan data perikanan rajungan di Indonesia. Dalam tulisan ini disajikan tentang rancang bangun kerekayasaan dan uji alat pengukur karapas rajungan. Tujuan kegiatan adalah merancang desain alat pengukur karapas rajungan dengan ukuran karapas $8-10 \mathrm{~cm}$ dan melakukan tahap konstruksi alat pengukur karapas sebagai alat bantu yang dapat dioperasikan pada penangkapan rajungan. Konstruksi alat ukur karapas rajungan dibuat mudah, sederhana dan murah, sehingga setiap komponen masyarakat yang bergerak di bidang penangkapan rajungan dapat menggunakan alat ukur karapas tersebut.

\section{POKOK BAHASAN Lokasi dan Waktu}

a. Pelaksanaan kegiatan rancang bangun dilaksanakan di Balai Besar Penangkapan Ikan (BBPI) Semarang pada tanggal 09 sampai dengan 26 Maret 2016. Rancang bangun meliputi : pembuatan master alat pengukur karapas rajungan, pembuatan moulding (cetakan) terakhir pembuatan alat pengukur karapas itu sendiri.

b. Setelah kegiatan rancang bangun selesai selanjutnya dilaksanakan kegiatan ujicoba aplikasif dilapangan perihal penggunaan alat pengkur karapas rajungan yang dilaksanakan pada tanggal 13 - 19 Juni 2017 yang berlokasi di Desa Betahwalang, Kecamatan Bonang - Kabupaten Demak.

\section{Bahan dan Alat}

a. Bahan pembuatan komponen rancang bangun alat pengukur karapas rajungan terdiri atas silikon rubber, resin epoxy, resin biasa, katalis dan peralatan perbengkelan serta peralatan pendukung lainnya.

b. Sampel rajungan (Portunus pelagicus) sebanyak 15 ekor dari masing-masing nelayan. Jumlah nelayan sebanyak 100 orang, sehingga jumlah tottal sampel sebanyak 1490 ekor rajungan.

c. Desain Rancang Bangun alat pengukur karapas rajungan (Gambar 1 dan 2).

d. Peralatan yang digunakan dalam kegiatan ujicoba aplikatif antara lain: mistar, kalkulator, kamera digital, alat tulis dan formulir untuk mencatat data. 


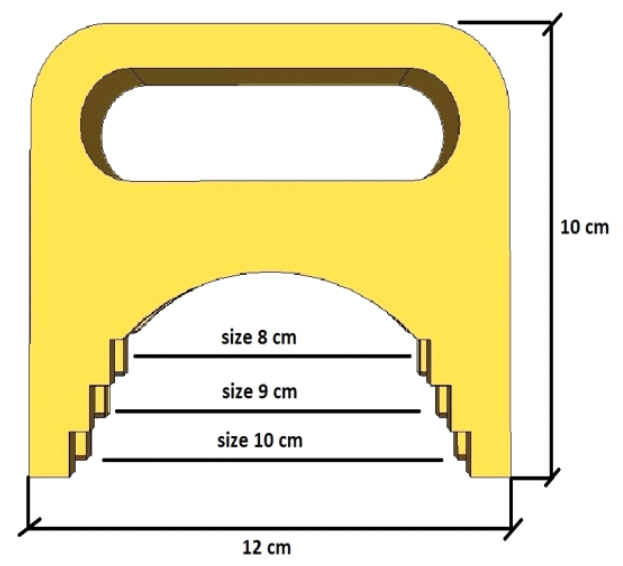

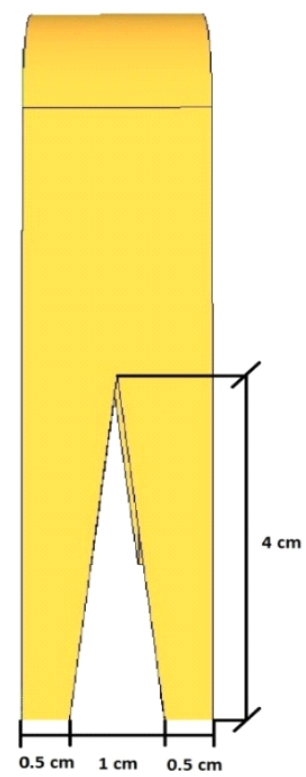

TEBAL

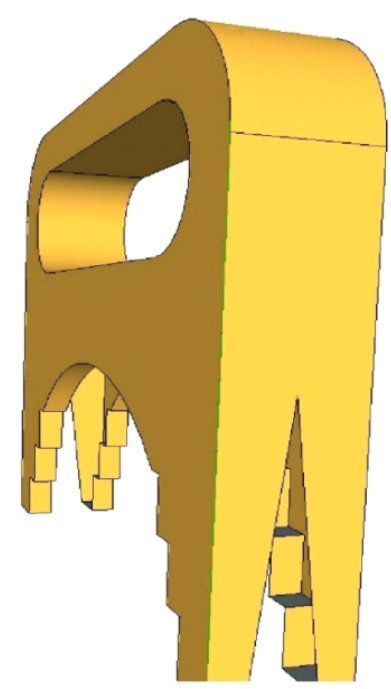

Gambar 1. Desain ukuran alat pengukur karapas rajungan
Gambar 2. Alat pengukur karapas rajungan (dari samping), berbetung $\mathrm{V}$ terbalik yang berfungsi agar bagian ujung karapas yang berbentuk runcing bisa masuk dalam alat ukur.

$\begin{array}{llcl}\begin{array}{l}\text { Keterangan } \\ \text { panjang }\end{array} & : & 12 \mathrm{~cm} & \begin{array}{l}\text { Kete } \\ \text { tinggi }\end{array} \\ \begin{array}{l}\text { tebal alat } \\ \text { lebar karapas } \\ \text { rajungan }\end{array} & : & 10 \mathrm{~cm} & \text { tebal } \\ \text { ahapan Pembuatan } \\ \text { Rajungan }\end{array}$

Tahapan pembuatan alat pengukur karapas rajungan, terbagi menjadi 3 tahapan yaitu (1) pembuatan model / master alat ukur karapas rajungan, (2) inti cetakan / moulding, dan (3) alat ukur karapas rajungan.

\section{(1). Pembuatan Model / Master Alat Ukur Karapas Rajungan.}

Pembuatan model / master alat ukur karapas rajungan ada 2 proses, pertama master alat terbuat dari bahan akrilik, pembuatan master dikerjakan oleh indrustri yang bergerak dibidang kerajinan dari bahan akrilik dengan menyertakan gambar desain master alat pengukur karapas rajungan. Kedua, membuat sendiri master alat pengukur karapas rajungan dari bahan papan kayu. Master alat pengukur karapas ini di desain dan dirancang untuk pengukuran karapas rajungan dari ukuran $8-10 \mathrm{~cm}$. Pada desain sebelumnya dimana alat ukur ini sudah dibuat dan diuji coba, namun setelah pelaksanaan uji coba terdapat kendala dimana untuk mengukur karapas rajungan dengan ukuran $8 \mathrm{~cm}$ masih terbentur pada sudut ketinggian pada sisi alat, sehingga diperlukan perbaikan desain dan pembuatan alat baru.

Adapun alat ini dibuat dengan panjang $12 \mathrm{~cm}$ dan lebar $10 \mathrm{~cm}$ serta ketebalan $2 \mathrm{~cm}$, berikut tahapan pembuatan model / master alat pengukur karapas dari bahan papan kayu (Gambar 3):

1. Memotong kayu papan dengan ukuran sesuai gambar desain $(12 \times 10 \times 2 \mathrm{~cm})$ lebihkan kira-kira 3 $\mathrm{mm}$ untuk proses finishing

2. Melubangi papan kayu sesuai ukuran pada desain oval yang nantinya berfungsi sebagai pegangan

3. Meratakan / menghaluskan setiap sisi atau bagian dengan menggunakan kikir, proses penghalusan / perataan dengan mengamplas pada setiap bagian

4. Setelah master alat pengukur karapas rajungan terbentuk, selanjutan nya dengan membuat bahan dempul. 
5. Melakukan pelapisan seluruh permukaan dengan dempul ini berfungsi untuk mendapatkan ukuran yang presisi, dempul dibiarkan kering kira- kira 1 jam , kemudian ratakan dengan menggunakan amplas ulangi proses tersebut sampai ukuran alat benar - benar presisi dan sesuai ukuran pada gambar desain.

6. Finishing proses pengecatan dengan cat jenis poxy. Ditunggu hingga kering dan master alat pun sudah siap untuk dicetak pada moulding.
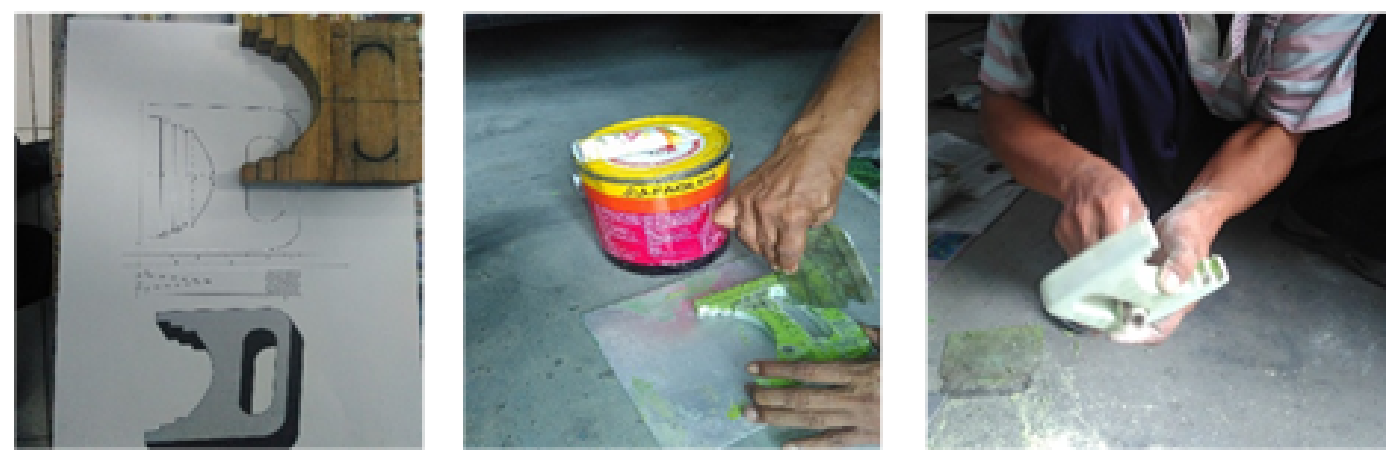

Gambar 3. Proses pembuatan master alat pengukur karapas rajungan.

(2) Pembuatan Inti cetakan / Moulding alat pengukur karapas rajungan.

Bahan pembuatan cetakan terbuat dari silicon rubber. Keunggulan silikon rubber yaitu dapat menghasilkan cetakan yang fleksibel, terperinci, bisa membuat cetakan yang paling rumit, dan tahan lama. Tahan terhadap bahan kimia. dan bisa dibuat dengan cepat, serta bisa mengering pada temperatur ruangan. Untuk membuat cetakan yang lebih keras, bisa menambahkan pengeras atau katalis. bahan yang yang paling umum adalah RTV (Room Temperature Vulcanizing). RTV dipilih agar detail dari model yang dibuat dapat tercetak dengan sempurna, bahan ini dapat masuk kedalam celah-celah detail model. Inti cetakan / Moulding berfungsi untuk mempertahankan detail alat ukur karapas rajungan agar tidak berubah atau tetap sama seperti model (master) alat ukur karapas rajungan yang dibuat. Inti cetakan / Moulding dibuat dari bahan silicon rubber yang mempunyai sifat elastis dan mampu membuat detail persis seperti model.

Untuk pembuatan cetakan alat ukur karapas rajungan 3 dimensi, dibuat dengan dua versi, yang pertama dengan satu bagian cetakan, versi yang kedua membagi dua yaitu bagian atas dan bawah yang dibuat terpisah agar waktu membukanya lebih mudah. Untuk pelaksanaan kegiatan pembuatan desain dan konstruksi inti cetakan / Moulding alat pengukur karapas rajungan diperlukan peralatan perbengkelan, bahan penunjang antara lain: lembaran akrilik, plat alumunium, lilin mainan, lemalteko, wadah pencampur, alat pengaduk. Setelah semua bahan yang diperlukan dan peralatan kerja yang akan digunakan untuk pembuatan desain dan konstruksi Inti cetakan / Moulding alat pengukur karapas rajungan sudah tersedia, maka langkah selanjutnya adalah menyusun rangkaian bahan pembuatan, sebagai berikut:

1) Memotong lembaran akrilik ukuran $15 \mathrm{~cm} \times 15$ cm sebanyak 4 (empat) potongan.

2) Membuat kubus dari potongan akrilik $15 \mathrm{~cm} \times 15$ $\mathrm{cm}$

3) Potong lembaran plat alumunium dengan ukuran $20 \mathrm{~cm} \times 20 \mathrm{~cm}$ sebagai alas cetakan

4) Menggabungkan potongan lembaran akrilik dengan lemalteko sehingga membentuk kubus, letakkan diatas plat alumunium $20 \mathrm{~cm}$ x $20 \mathrm{~cm}$, kemudian lapisi bagian luarnya dengan menggunakan lilin mainan.

5) Melapisi seluruh permukaan model / master alat pengukur karapas rajungan dengan mirror graze untuk mencegah silikon rubber lengket, kemudian masukan kedalam cetakan kubus yang telah di buat, atur model / master alat ukur karapas rajungan hingga posisi simetris.

6) Mencampur bahan silicone rubber type RTV 285 part A sebanyak $0,35 \mathrm{~kg}$ dan part B sebanyak $0,35 \mathrm{~kg}$ kedalam wadah. Setelah tercampur, aduk bahan tersebut secara perlahan sampai rata.

7) Silikon rubber yang telah teraduk dan tercampur rata dituangkan kedalam cetakan kubus. Usahakan silicon rubber tertuang rata dalam cetakan, ditunggu sampai kering kira-kira 12 s.d 18 jam, setelah kering lepaskan sisi-sisi potongan akrilik sebagai bahan casing cetakan. Jika kurang baik dilakukan ulang.

8) Untuk versi inti cetakan / Moulding dua bagian, prosesnya sama dari langkah 1 s.d 7 , yang membedakan adalah model / master alat pengukur karapas dibuat dua tahap (bagian atas dan bagian bawah). 


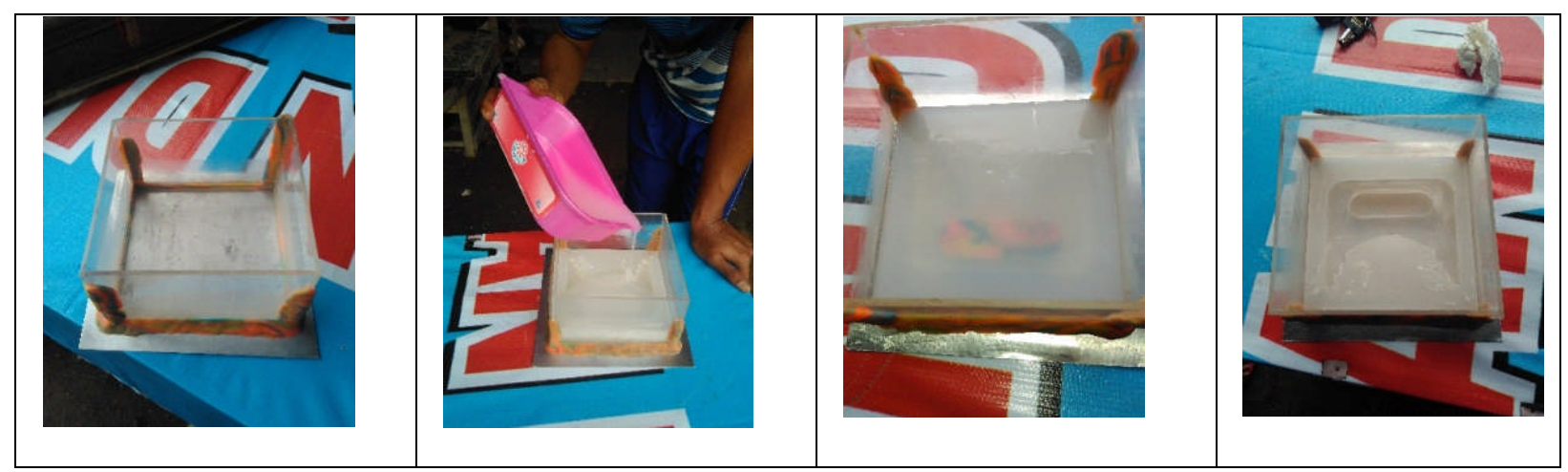

Gambar 4. Proses pembuatan inti cetakan/ moulding alat pengukur karapas rajungan.

\section{(3) Pembuatan Alat Pengukur Karapas Rajungan}

Bahan pembuatan alat pengukur karapas rajungan terbuat dari resin epoxy. Keunggulan resin epoxy yaitu Kata "Epoxy" identik dengan Cat,lem,pelapis lantai. Resin epoxy memiliki keunggulan yaitu permukaan yg halus, lebih tahan terhadap cuaca dan beberapa bahan kimia. Untuk pembuatan alat ukur karapas rajungan diperlukan bahan resin epoxy yang terdiri 2 jenis yang di gabungkan dengan perbandingan 1:1 (bagian A dan bagian B). Jenis resin yang dipakai adalah epoxy tipe GP 777 A dan GP 777 B. Sama hal nya saat pembuatan cetakan/moulding, saat pembuatan alat pengukur karapas rajungan diperlukan peralatan perbengkelan, bahan penunjang antara lain: cetakan/ moulding, lilin mainan, wadah pencampur, alat pengaduk. Setelah semua bahan yang diperlukan dan peralatan kerja yang akan digunakan untuk pembuatan alat pengukur karapas rajungan sudah tersedia, maka langkah selanjutnya adalah menyusun rangkaian bahan pembuatan, sebagai berikut:

1) Membersihkan moulding /cetakan dari debu dan kotoran.

2) Menyiapkan resin epoxy type GP 777

3) Menyiapan wadah pencampur dan alat pengaduk

4) Mencampur bahan resin epoxytype GP 777 bagian A sebanyak $0,15 \mathrm{~kg}$ dan bagian B sebanyak $0,15 \mathrm{~kg}$ kedalam wadah. Setelah tercampur, aduk bahan tersebut secara perlahan sampai rata

5) Melapisi moulding/cetakan dengan mirror graze

6) Menuangkan resin epoxy kedalam moulding / cetakan secara perlahan dan merata.

7) Ditunggu reaksinya sampai kering kira-kira 4-5 jam, kemudian dilepaskan dengan menekan secara perlahan dari mouding/cetakan.

8) Finishing,cetakan di haluskan dengan mengamplas.

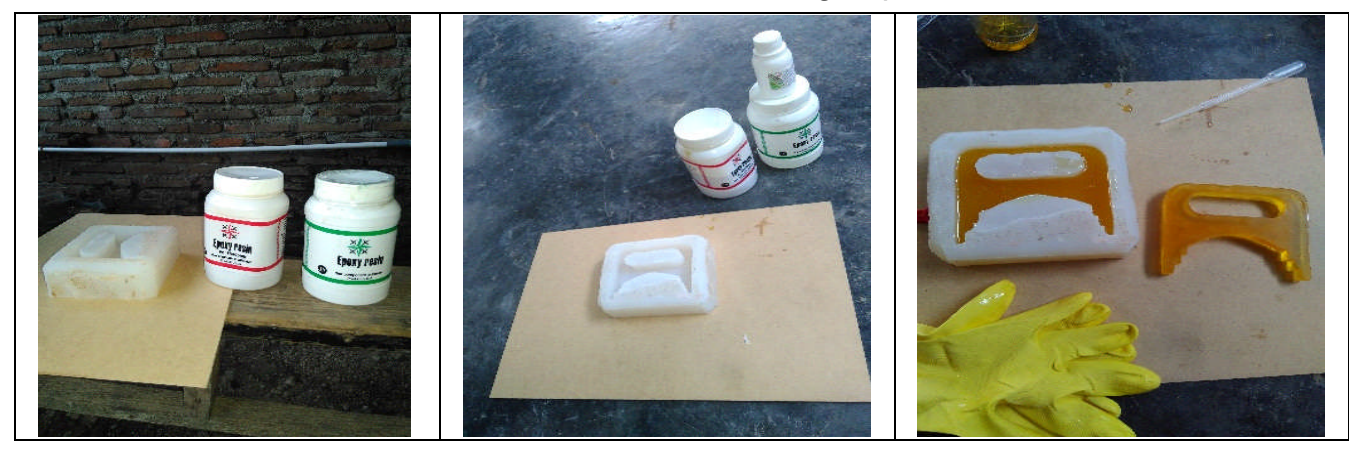

Gambar 5. Proses pembuatan alat pengukur karapas rajungan.

\section{Uji Coba Alat}

Uji coba alat pengukur karapas rajungan dilakukan dengan 2 tahapan, meliputi

\section{(1) Pengumpulan Data}

Metode yang digunakan dalam pelaksanaan kegiatan Uji coba Alat Bantu pengukur karapas rajungan di Perairan Pantai Utara Jawa Tengah Tahun
2016 adalah "Metode Exploratory Survey". Komponen utama pada kegiatan ini adalah sampel rajungan dari hasil tangkapan nelayan menggunakan alat tangkap bubu. Pengukuran karapas rajungan secara langsung di lokasi penangkapan rajungan, pengukuran dilakukan dengan cara yang benar untuk mendapatkan data yang akurat. Data primer yang diambil berupa data teknis meliputi jenis kelamin rajungan dan ukuran lebar karapas. Hasil tangkapan rajungan dari setiap nelayan (sebanyak 100 nelayan) 
ditimbang secara keseluruhan, kemudian diambil secara random sebanyak 15 ekor, kemudian dicatat kedalam lembaran kertas survei.

\section{(2) Teknik Pegukuran Karapas Rajungan}

Teknik pengukuran karapas pada rajungan hampir sama saat pengukuran karapas pada kepiting, yang perlu diperhatikan adalah bentuk karapas pada rajungan yang kedua sisinya runcing. Pada rancang bangun alat sudah didesain pada sisi samping alat yang berbentuk $\mathrm{V}$ terbalik sehingga saat dilakuan ujicoba pengukuran sisi runcing pada karapas rajungan bisa masuk pada alat pengukur karapas rajungan.(Gambar 6 dan Gambar 7)

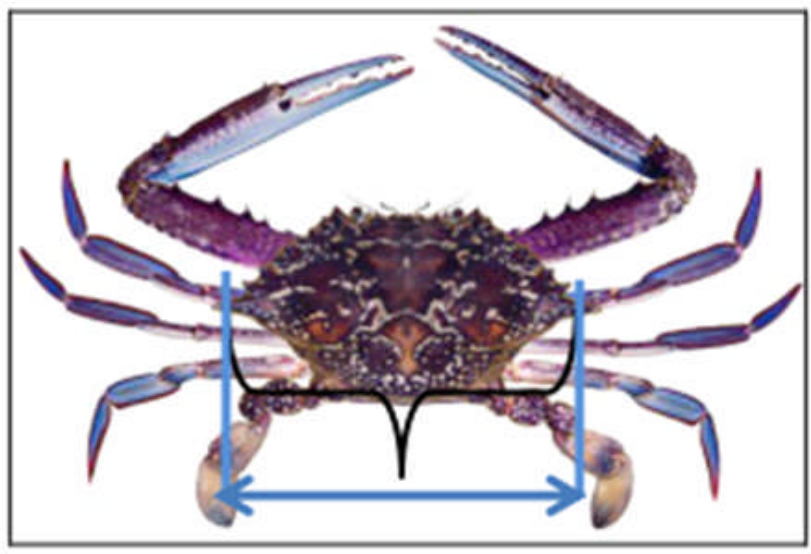

Gambar 6. Lebar Karapas rajungan (Portunus pelagicus spp)

Sumber: PermenKP No.1 Tahun 2015

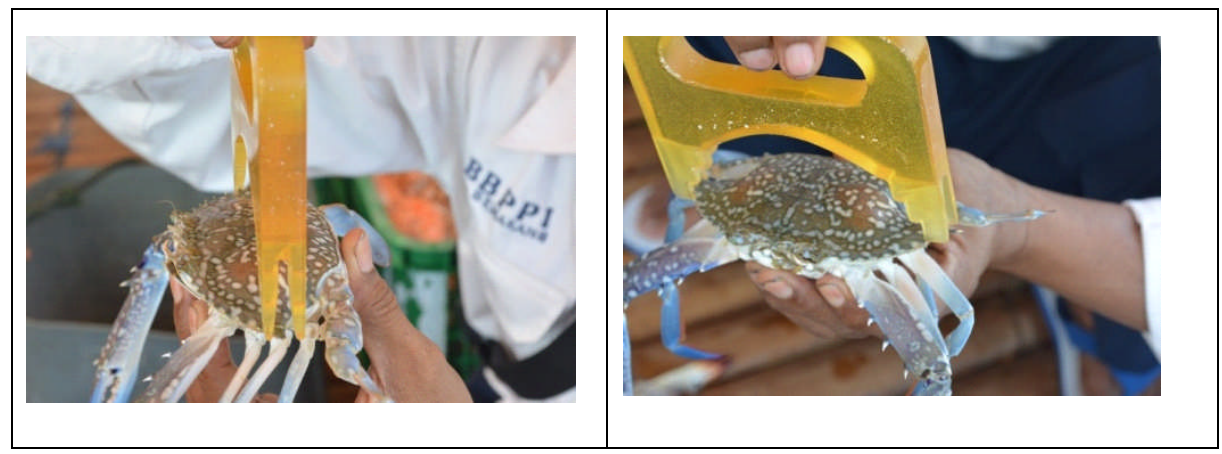

Gambar 7. Pengukuran karapas rajungan.

Estimasi waktu pengukuran dengan menggunakan alat ukur karapas rajungan adalah 4-8 detik, sedangkan dengan menggunakan mistar waktu yang dibutuhkan 7-12 detik. Pengukuran karapas rajungan menggunakan metode pembulatan $0.5 \mathrm{~cm}$ dengan menggunakan mistar untuk mengetahui ukuran sebenarnya.

\section{Hasil}

Jumlah total sampel rajungan sebanyak 1490 ekor terbagi menjadi 3 kelompok yaitu betina tidak bertelur sebanyak 519 ekor (35\%), jantan 759 ekor (51\%) dan betina bertelur sebanyak 212 ekor (14\%), selanjutnya yang dianalisa hanya rajungan betina tidak bertelur dan jantan (Gambar 8,9, dan10). Untuk rajungan betina bertelur tidak diukur, dikarenakan sesuai dengan PerMen KP. 01/Tahun 2015, rajungan yang bertelur harus dilepaskan.
Pada Gambar 9. lebar karapas rajungan betina bertelur tertinggi $15 \mathrm{~cm}$, sedang yang terendah $8 \mathrm{~cm}$, sedangkan dominasi ukuran lebar karapas rajungan $8-10 \mathrm{~cm}$. Lebar karapas tertinggi pada rajungan betina tidak bertelur $15 \mathrm{~cm}$, terendah $8 \mathrm{~cm}$, sedangkan rata-ratanya adalah $10,406 \mathrm{~cm}$.

Pada Gambar 10. lebar karapas rajungan jantan tertinggi $14 \mathrm{~cm}$, sedang yang terendah $7.5 \mathrm{~cm}$, sedangkan dominasi ukuran lebar karapas rajungan jantan $8-10 \mathrm{~cm}$. Pengubahan desain ukuran yang semula $10-12 \mathrm{~cm}$ diubah menjadi $8-10 \mathrm{~cm}$ dikarenakan ukuran lebar karapas rajungan yang di dapat dari nelayan desa Betahwalang dari total 1490 ekor sampling, $20 \%$ masih di bawah $10 \mathrm{~cm}$. Hasil sampling Rajunganjantan sebanyak 759 ekor (51\%) dengan lebar karapas tertinggi $14 \mathrm{~cm}$ dan terendah $7.5 \mathrm{~cm}$, rata-rata $10,557 \mathrm{~cm}$. 


\section{= Jantan = Betina tidak bertelur $=$ Betina bertelur}

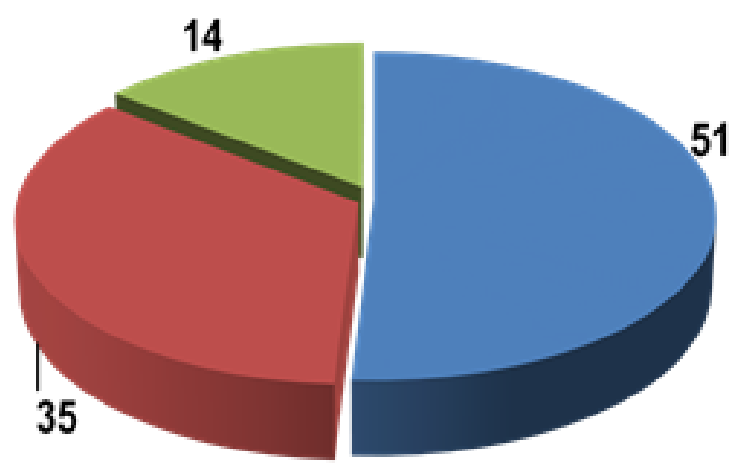

Gambar 8. Komposisi rajungan.

BETINA TIDAK BERTELUR

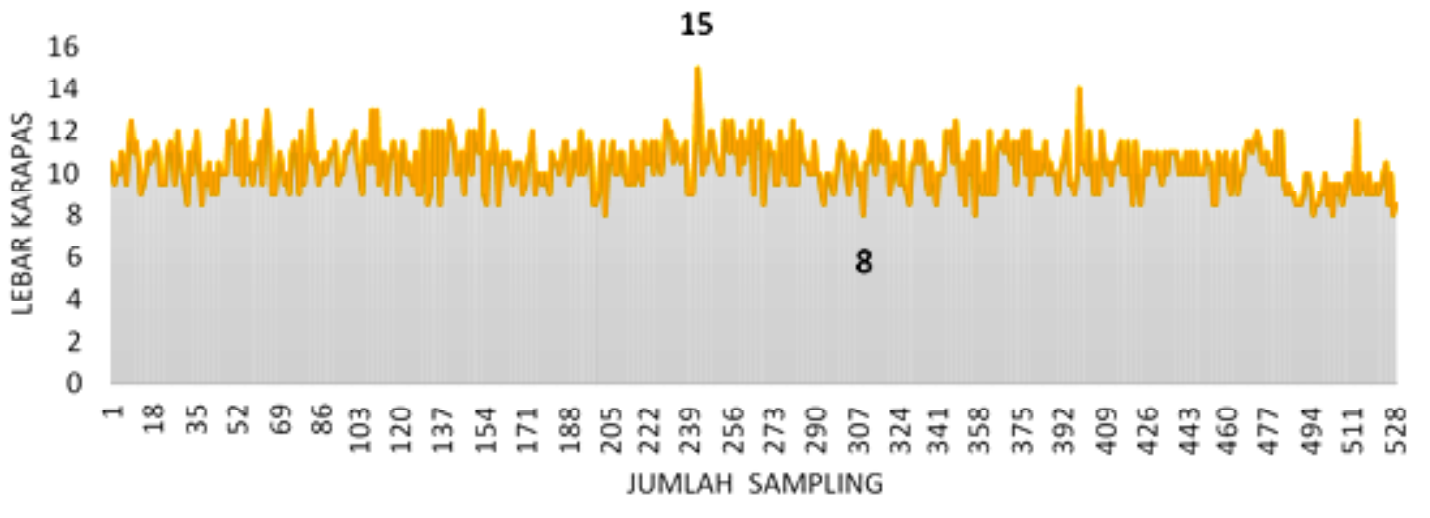

Gambar 9. Ukuran lebar karapas rajungan betina tidak bertelur sebanyak 519 ekor (35\%).

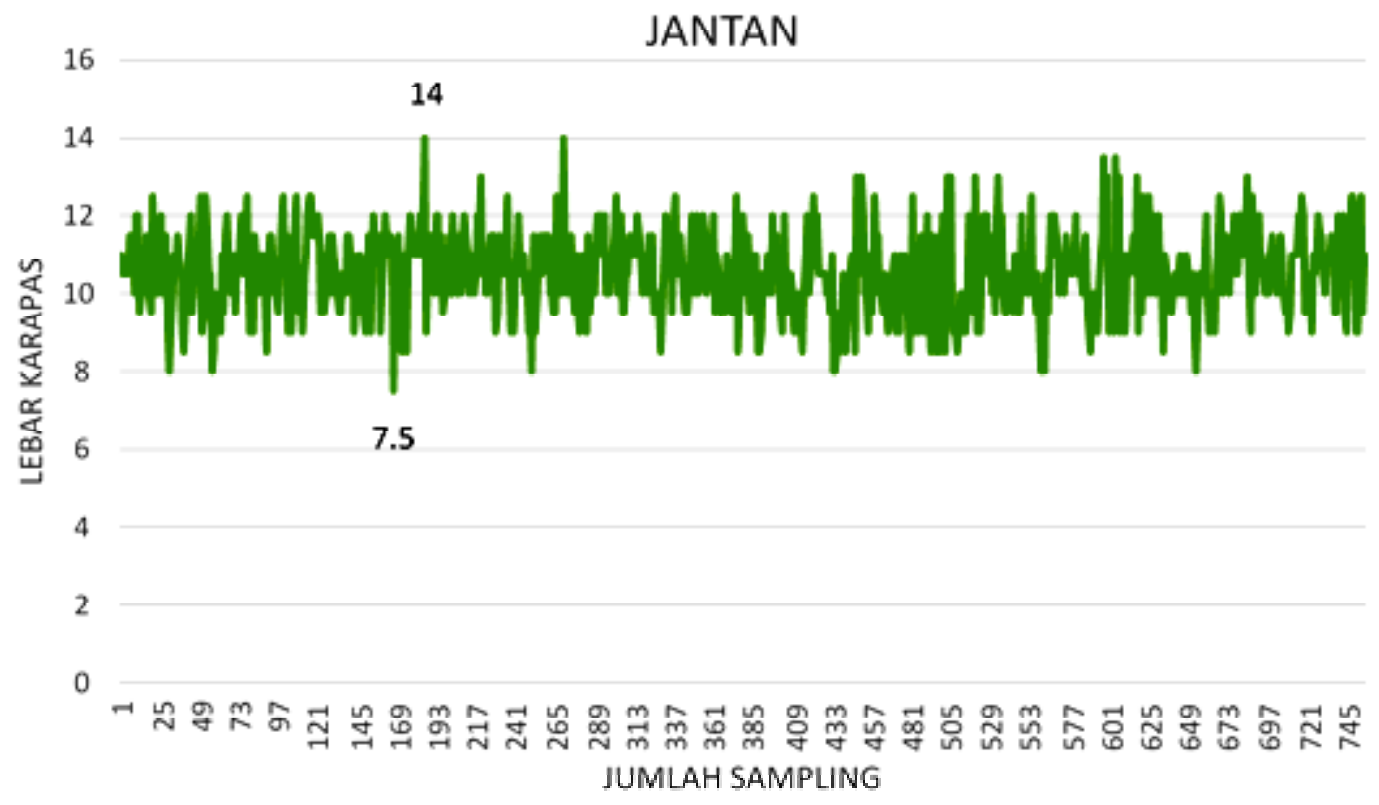

Gambar 10. Ukuran lebar karapas rajungan jantan sebanyak 759 ekor (51\%). 


\section{KESIMPULAN}

Rancang bangun kerekayasaan alat pengukur karapas rajungan yang dilakukan di BPPI Semarang yang telah diuji coba di perairan pantai utara Jawa Tengah, yaitu di desa Betahwalang, Kabupaten Demak. Alat tersebut merupakan alat pengukur lebar karapas rajungan yang mudah dan sederhana serta akurat. Hasil pengukuran lebar karapak rajungan diberbagai lokasi dengan menggunakan alat tersebut dapat digunakan untuk mendapatkan stok rajungan baik lokal maupun nasional.

\section{SARAN}

Agar mudah dikenal, maka alat pengukur karapas rajungan perlu dan penting diberi nama.

\section{PERSANTUNAN}

Terimakasih atas dukungan Balai Besar Penangkapan Ikan Direktorat Jenderal Perikanan Tangkap yang telah memberikan kesempatan untuk melakukan perancangan dan kerekayasaan serta pengujian Alat pengukur karapas rajungan. Penghargaan yang tinggi pada nelayan Desa Betahwalang dan instansi terkait (Dinas Kelautan Perikanan Kabupaten Demak, Perangkat Desa Betahwalang) atas kerjasama yang telah banyak memberikan bantuan fasilitas selama kegiatan di Perairan Pantai Utara Jawa Tengah.

\section{DAFTAR PUSTAKA}

BPS (Badan Pusat Statistik) Kabupaten Demak. 2015. Demak dalam Angka. BadanPusatStatistik (BPS) Kabupaten Demak, Katalog BPS No. 1102001.3321.
Istikasari, I., A. K. Mudzakir. \& D. Wijayanto. 2015. Analisis Bioekonomi Rajungan (Portunus Pelagicus) Menggunakan Pendekatan Swept Area Dan Gordon-Schaefer di Perairan Demak. Journal of Fisheries Resources Utilization Management and Technology Vol. 4, No.4:29-38.

KKP (Kementerian Kelautan dan Perikanan). 2015. Peraturan Menteri Kelautan dan Perikanan Nomor 1/PERMEN-KP/2015 tentang PENANGKAPAN LOBSTER (Panulirus spp.), KEPITING (Scylla spp.), DAN RAJUNGAN (Portunus pelagicus spp.), Jakarta.

KKP (Kementerian Kelautan dan Perikanan). 2016. Keputusan Menteri Kelautan dan Perikanan Nomor 47/KEPMEN-KP/2016 tentang Estimasi Potensi, Jumlah Tangkapan Yang Diperbolehkan, Dan Tingkat Pemanfaatan Sumber Daya Ikan Di Wilayah Pengelolaan Perikanan Negara Republik Indonesia, Jakarta.

Zaenal. A., A.N. Bambang., D. Wijayanto. 2014. Manajemen Kolaboratif Untuk Introduksi Pengelolaan Rajungan Yang Berkelanjutan Di Desa Betahwalang Demak. Journal of Fisheries Resources Utilization Management and Technology Vol. 3, No.4:29-36. 